\title{
Cómo se representa la información fonológica en el cerebro: una explicación en términos de las redes relacionales
}

\section{Representation of phonological information in the brain: a $n$ explanation in terms of relational networks}

\section{José María Gi \\ Doctor en Filosofía \\ Profesor Adjunto \\ Universidad Nacional del Mar de \\ Plata \\ Investigador Adjunto, CONICET \\ Argentina}

\section{RESUMEN}

Gracias a la afasiología y a la neuroanatomía sabemos que hay dos sistemas fonológicos: la percepción fonológica (en el área de Wernicke) y la producción fonológica (en el área de Broca). Por otro lado, gracias a la lingüística sabemos que el sistema léxico-gramatical conecta los significados con la fonología. A partir de todo esto se espera mostrar que las redes relacionales ${ }^{1,2,3,4,5}$ permiten representar cómo se conectan los dos sistemas fonológicos, el léxico-gramatical y el semántico.

Palabras claves: percepción fonológica, producción fonológica, léxico-gramática, significados, redes relacionales.

\section{ABSTRACT}

Thanks to aphasiology and neuroanatomy, it is known that there are two phonological systems: phonological perception (in Wernicke's area) and phonological production (in Broca's area). On the other hand, thanks to Linguistics, we know that the lexicogrammatical system connects meanings with phonology. On this basis, this report aims at showing the way in which relational networks ${ }^{1,2,3,4,5}$ allow us to represent how the two phonological systems, lexico-grammatical and semantics, are connected.

Key words: phonological perception, phonological production, lexico-grammar, meanings, relational networks.
Contacto con el autor: José María Gi Alberti 190 (7600) Mar del Plata, Provincia de Buenos Aires, Argentina

Correo-e: josemaria@gilmdq.com

Recibido: $10 / 03 / 2014$

Aceptado: 22/10/2014 


\section{Introducción}

"The arcuate fasciculus provides the best example of an important problem that needs to be considered by anyone attempting to build a theory of how linguistic information is represented -in the brain or abstract".

$$
\text { Sydney Lamb }{ }^{6}
$$

En este trabajo se espera mostrar cómo se representa la información fonológica en el sistema lingüístico real de una persona cualquiera. El punto de partida es el siguiente conjunto de hipótesis que ya se han comprobado.

a) Hay un sistema de percepción fonológica, cuyo asiento biológico está en el área de Wernicke.

b) Hay un sistema de producción fonológica, cuyo asiento biológico está en el área de Broca.

c) Los dos sistemas fonológicos (el de percepción y el de producción) se conectan directamente entre sí por medio de un tracto de fibra blanca, el fascículo arqueado.

d) El sistema léxico-gramatical es el sistema intermedio gracias al cual los significados se conectan con la fonología.

No es imprudente aceptar que las hipótesis (a) y (c) están confirmadas desde hace tiempo gracias a contribuciones de la afasiología y la neuroanatomía. Por su parte, la hipótesis (d) puede considerarse confirmada gracias a la observación de la evidencia lingüística.
La teoría de redes relacionales $s^{1,2,3,4,5}$ ofrece un sistema de notación que nos permitirá, sobre la base del conjunto de hipótesis (a) - (d), alcanzar el objetivo de este trabajo: empezar a entender cómo se representa la información fonológica en el sistema lingüístico del cerebro.

A continuación se revisan algunas de las implicancias fundamentales del conjunto de hipótesis con el que se está trabajando.

\section{Acerca de la percepción en general y de la percepción fonológica en particular}

Para entender la percepción fonológica en el contexto del sistema lingüístico debería advertirse, antes que todo, que la percepción en general no funciona en un solo sentido, "de abajo hacia arriba" (desde la percepción "pura" a "las ideas"), sino que es bidireccional. En efecto, prácticamente toda la corteza cerebral está disponible para cualquier actividad de procesamiento de información y esto incluye los procesos perceptivos. Por ejemplo, la percepción visual no depende exclusivamente de la corteza visual, sino también de otras áreas corticales, las motoras incluso. Así, lo que vemos está condicionado por lo que concebimos acerca del mundo: si veo la cabeza de un gato asomada por la pared, mi sistema conceptual me lleva a pensar que el resto del felino está detrás de la pared, aunque mi sistema visual no haya percibido el resto del animal. En otras palabras, la percepción pura no me lleva a concebir que la cabeza del gato está flotando sin el resto del cuerpo. 
De especial interés para la lingüística es que la percepción auditiva no depende solo de la corteza auditiva. Cualquier parte de la corteza guarda alguna clase de conexión con otra parte de la corteza y las diferentes partes de la corteza son capaces de trabajar de forma paralela. Por ello, la percepción del habla tiene lugar en una variedad de subsistemas corticales. Por ejemplo, nuestros conceptos acerca de quién habla inciden en la percepción del habla en virtud de un proceso "de arriba hacia abajo" (en este caso, en la ruta que va desde los significados hacia la percepción).

En un principio a muchos puede resultarles sorprendente que las estructuras motoras estén involucradas en la percepción, así como también que las habilidades perceptivas se usen en la actividad motora. Pero en efecto las cosas son así. El neurolingüista norteamericano Sydney Lamb, creador de la teoría neurocognitiva, sugiere que es necesario distinguir la "micropercepción" de la “macropercepción” ${ }^{6}$. La micropercepción en la visión, por ejemplo, es parte del procesamiento visual desplegado exclusivamente por la corteza visual. La macropercepción en la visión, en tanto, es el proceso global de percepción visual, para el cual contribuyen otras áreas de la corteza. De modo análogo, podemos distinguir la microproducción o procesamiento micromotor, de la macroproducción o procesamiento macromotor.

En lo que respecta al procesamiento de la información fonológica puede establecerse lo siguiente:

- La micropercepción del habla tiene lugar en el área de Wernicke (área de reconocimiento fonológico).
- La microproducción del habla tiene lugar en el área de Broca (área de producción fonológica).

- La macropercepción del habla se despliega en muchas áreas de la corteza.

- La macroproducción del habla se despliega en muchas áreas de la corteza.

Algunos investigadores muy calificados llegaron a plantear que la hipótesis según la cual la (micro) percepción del habla se localiza en el área Wernicke es falsa porque los pacientes con afasia de Wernicke también producen enunciados defectuosos. En otras palabras, si lo que se dañó (a causa de un ataque cerebral o un accidente) es la zona del reconocimiento fonológico, ¿por qué los afásicos de Wernicke también manifiestan inconvenientes en la producción del habla, cuya zona no está dañada? En este sentido, el eminente neurólogo Harold Goodglass (que no es detractor de la hipótesis de Wernicke) ofrece este fragmento de discurso de un paciente con afasia de Wernicke:

"I feel very well. My hearing, writing been doing well. Things that I couldn't hear from. In other words, I used to be able to wok cigarettes I didn't know how... Chesterfeela, foe 20 years I can write it ${ }^{\prime 7,8}$.

Solo como para dar una idea aproximada, el ejemplo provisto por Goodglass podría traducirse de la siguiente manera a nuestra lengua:

"Me siento muy bien. Mi escuchar, escribir estado haciendo bien. Cosas que no podía oír. En otras palabras, antes yo era capaz de suma 
cigarrillos no sabía cómo... Chesterfila, poro 20

años lo puedo escribir".

La reconocida lingüista Sheila Blumstein ${ }^{9}$ ha planteado que, como los pacientes con daños en el área de Wernicke tienen un habla defectuosa, debe ser falsa la hipótesis de que dicha área se usa para el reconocimiento y que el área de Broca se usa para la producción. En la misma línea, otro lingüista muy destacado como Steven Pinker, escribe lo siguiente:

"[Wernicke's area] was once thought to underlie language comprehension. But that would not explain why the speech of these patients sounds so psychotic ${ }^{\prime 10}$.

Pinker llega a afirmar que "para ser sinceros", nadie sabe de verdad para qué sirven las áreas de Broca y Wernicke.

Antes que todo habría que decir que en el siglo XIX Carl Wernicke ya estaba al tanto de cuestionamientos análogos a los de Blumstein y Pinker. En efecto, ya Wernicke ${ }^{11}$ advirtió que los pacientes tenían alterada la comprensión del habla porque habían sufrido daños cerebrales en el área cortical que luego llevó su nombre (área de Wernicke). Pero también advirtió que los pacientes manifestaban problemas en la producción del habla, aunque no se registraran daños en el área de producción (el área de Broca). A pesar de lo que sugieren Blumstein y Pinker, la explicación del vínculo entre estos fenómenos es bastante simple: el sistema de reconocimiento fonológico es necesario para monitorear el proceso del habla. En otras palabras, el sistema de producción fonológica está controlado por el sistema de reconocimiento fonológico. En general necesitamos una habilidad de comprensión intacta para monitorear nuestra producción. Por lo tanto, el área de Wernicke sí desempeña un papel importante en la producción y ese papel es precisamente el del reconocimiento.

Lamb $^{8}$ destaca que si queremos advertir la importancia del reconocimiento en la producción, debemos tratar de escribir o dibujar sin mirar el papel y luego comparar el resultado con la calidad de la escritura o del dibujo que hacemos cuando miramos el papel. En este sentido, a Blumstein y a Pinker podría preguntárseles cuán bien toca un sordo un instrumento musical, cuán bien puede pintar un ciego o si les gustaría andar en un auto manejado por una persona que se quedara ciega repentinamente a causa de un ataque, aun cuando todas las habilidades motoras de esa persona se mantuvieran intactas.

Para trazar un paralelo más estrecho con una persona que ha sufrido un daño en el área de Wernicke podríamos pensar en la capacidad de pintar de una persona que no es ciega, pero que por un daño en el lóbulo occipital ya no es capaz de formar imágenes visuales ni de reconocer objetos visualmente aun cuando no quedó ciega. Esta persona no solo carecería de la habilidad de visualizar al ir decidiendo qué colores usar y dónde aplicarlos, sino que también vería inmensamente disminuida su capacidad de percibir su propia pintura a medida que la fuera haciendo. De manera análoga, no hay razón para sorprenderse de que una persona con el reconocimiento fonológico dañado produzca un habla defectuosa o extraña. 
Así, cuando hablamos, contamos con dos senderos para el monitoreo auditivo:

- $\quad$ Sendero 1: percibimos nuestro propio discurso a través del aire gracias a un sendero que va desde la producción del habla hasta los oídos y al reconocimiento fonológico.

- $\quad$ Sendero 2: monitoreamos internamente nuestro propio discurso por medio del circuito del habla interna. Para ello usamos conexiones internas directas que van desde la producción articulatoria hasta la percepción auditiva y posiblemente también conexiones que van de la producción fonológica al reconocimiento fonológico.

Las Figuras 1 y 2 (tomadas de Lamb ${ }^{1}$ ) ilustran los dos puntos anteriores. Ambas representan la superficie exterior del hemisferio izquierdo. La Figura 1 muestra el área de producción fonológica (área de Broca), el área de reconocimiento fonológico (el área de Wernicke) y el fascículo arqueado, la fibra que conecta ambas zonas.

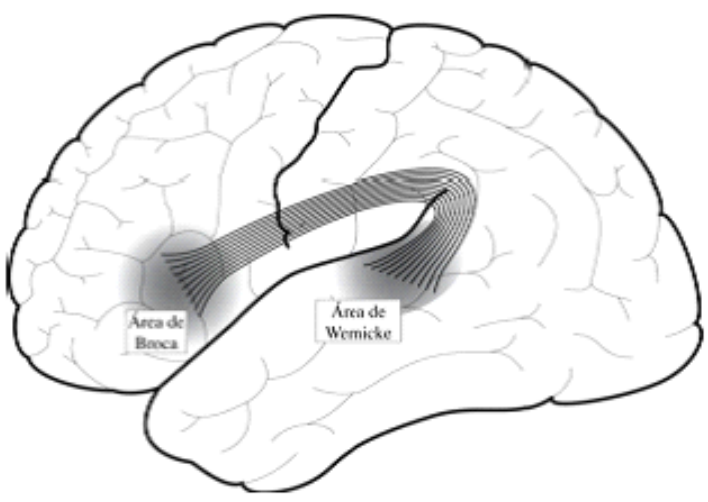

Figura 1. El área de Broca, el área de Wernicke y el fascículo arqueado $^{1}$.

La Figura 2, por su parte, representa las ubicaciones aproximadas de los nodos de reconocimiento fonológico (RF) y producción fonológica (PF), en relación con otros nodos localizables en diferentes subsistemas de la corteza. Los ejemplos de la Figura 2 se refieren al nodo para la palabra gato.

Experimentos con neuroimágenes funcionales ofrecen datos interesantes. A ciertos individuos se les muestra la foto de una mano y se les pregunta si es la derecha o la izquierda. Las imágenes funcionales muestran actividad en el lóbulo occipital, el responsable de la visión; pero también registran actividad en la corteza motora, precisamente en las partes que rigen los movimientos de las manos. Cuando hacemos esta tarea, nos imaginamos que ponemos una de las manos en la posición de la imagen para obtener una correspondencia.

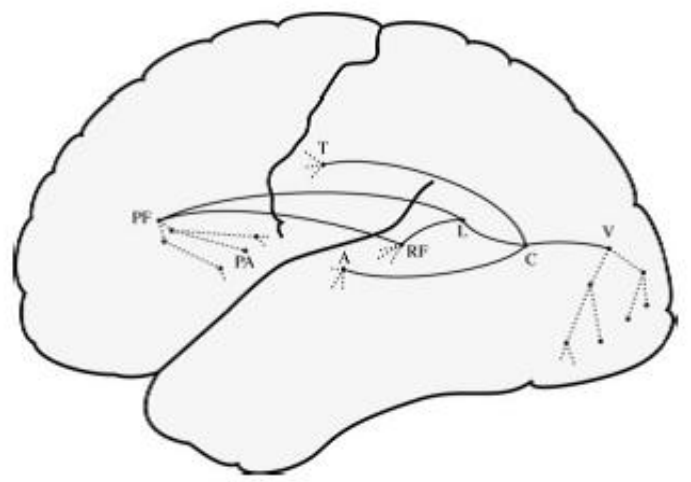

Figura 2. Ubicaciones aproximadas de los nodos de reconocimiento fonológico [RF] y de producción fonológica para gato1. C: nodo conceptual; $\mathrm{T}$ : táctil (cómo se siente un gato cuando se lo acaricia); A: reconocimiento auditivo (imagen auditiva) del maullido del gato; $\mathrm{V}$ : reconocimiento visual (o imagen) de un gato.

De esta forma, el sistema de reconocimiento fonológico (un sistema perceptivo) sí desempeña un rol en la producción: el reconocimiento. De un modo más apropiado:

- La micropercepción del habla en área de Wernicke desempeña un rol fundamental en la macroproducción del habla. 
- $\quad$ Por contrapartida, la corteza motora desempeña un rol importante en la percepción.

Al oír nuestro propio discurso usamos nuestro "rulo interno", que activa las áreas de reconocimiento y producción. En este contexto, el fascículo arqueado constituye un desafío de primer orden para cualquier investigador que busque construir una teoría de cómo se representa la información lingüística, tanto de forma material (en el cerebro) como de forma abstracta (en un modelo teórico)6. Es un hecho que si tengo la imagen acústica de [gáto] sé inmediatamente cómo decir gato. $Y$ también es un hecho que si digo gato en voz alta después puedo seguir diciendo esa palabra en "voz baja", "para adentro". Esto se explica en virtud de lo que hemos estado considerando: hay dos sistemas fonológicos; la producción fonológica procesa los rasgos articulatorios y el reconocimiento fonológico procesa los rasgos perceptivos.

Ahora bien, la transmisión de información depende de cómo se representa la información. Aquí tenemos que las hipótesis de la teoría de redes relacionales son consistentes con el gran número de fibras axónicas del fascículo arqueado:

"The node for the perceptual form is connected (locally, within Wernicke's area) to those for its perceptual features, and the corresponding node on the production side is connected to its articulatory features. It is necessary only to have a direct connection from the one to the other, a unique connection for every phonological form. And this solves the problem of why the arcuate fasciculus has so many fibres: It needs a separate fiber -or more likely, more than one for the sake of redundancy - for every phonological form represented in the system ${ }^{\prime \prime}$.

En la sección que sigue se expondrán los fundamentos de la teoría de redes relacionales, que se presenta como hipótesis plausible en términos neurológicos.

\section{Las redes relacionales como teoría neurológicamente plausible}

\section{La evidencia empírica inmediata y el sistema lingüístico interno}

El neurolingüística norteamericano Sydney M. Lamb considera que el interés por la evidencia empírica nos conducirá a una lingüística verdaderamente científica. En efecto, Lamb ${ }^{1,2,3,4,6}$ sugiere que no es empirista suponer que hay una cosa tal como "el lenguaje". Desde una perspectiva comparable a la de Quine ("lo que llamamos nuestro conocimiento (...) es una tela (...) que no está en contacto con la experiencia más allá que a lo largo de los lados"), Lamb afirma que el concepto de "lenguaje" es, en el mejor de los casos, algo muy abstracto, demasiado distante de la evidencia empírica más inmediata. Percibimos el habla y, en lenguas como la nuestra, está la palabra lenguaje: ¿podemos inferir a partir de esto que "existe el lenguaje"?

Un hecho observable y tangible es que los seres humanos se hablan unos a otros. Luego de 
apreciar eso, podríamos plantear estas dos hipótesis: el habla de los seres humanos es organizada y sistemática; y la comunicación es por lo general bastante efectiva.

No es contraria a una posición empirista la hipótesis de que las personas reales cuentan con un "sistema interno" que les sirve para su actividad lingüística. Ejemplos manifiestos de la actividad lingüística son conductas como hablar y comprender, leer y escribir, monologar interiormente, etc. Arribamos así a una definición elemental de "sistema lingüístico", algo modesta pero consistente con la evidencia empírica más básica:

"El sistema lingüístico de un individuo es un medio que le permite involucrarse en las actividades lingüísticas observables como hablar, entender, leer, escribir".

La tarea del lingüista - científico al fin - es examinar la naturaleza de ese medio, que debe ser interno al individuo. Como es razonable sugerir que ese sistema interno tiene su asiento en el cerebro, la lingüística pasa a tener una relación directa con la ciencia natural.

\section{Un sistema de notación para representar la información lingüística: redes relacionales}

A lo largo de sus trabajos, Lamb propone que toda la evidencia lingüística y neurológica es una muestra cabal de que la estructura lingüística de un individuo constituye una red, un sistema en el cual la información no está "almacenada", "depositada" o "archivada", sino localizada y a la vez distribuida en la conectividad. La idea encuentra sus raíces en las obras de los neurólogos Carl Wernicke ${ }^{11}$ y Norman Geschwind $^{13,14}$ y de los lingüistas Henry Sweet ${ }^{15}$, Jan Badouin de Courtenay ${ }^{16}$, Ferdinand de Saussure ${ }^{17}$ y Louis Hjelmslev ${ }^{18}$.

Para representar cómo se conecta la información de la red, se hace imprescindible un nuevo sistema de notación que Lamb reelabora a partir de las redes sistémicas de Michael Halliday ${ }^{19}$. Hoy en día, el mismo Halliday ${ }^{20}$ destaca que una gramática sistémica y funcionalista debe estar representada en el cerebro en los términos descritos por Lamb ${ }^{1}$.

La notación relacional permite advertir que la información lingüística está en la conectividad y que no hay objetos tales como oraciones, palabras, morfemas, fonemas, etc. Los rótulos escritos al lado de los nodos y las conexiones son justamente eso: indicadores de la conexión (así como son indicadores los carteles al costado de la ruta, pero no son parte de la ruta).

Ya se ha dicho que para la teoría neurocognitiva la información lingüística reside en la conectividad. Se ha dicho también que Lamb se inspira en las obras de Hjelmslev ${ }^{18}$ y Halliday ${ }^{19}$. Del primero toma la idea de que en el sistema lingüístico no hay unidades estáticas sino relaciones; del segundo, el tipo de notación usado para la gramática sistémico-funcional, gracias al cual se distinguen claramente las relaciones sintagmáticas ("ambos/y") y las relaciones paradigmáticas ("uno u otro/o"). De esta manera, si se identifican las relaciones inmediatas de una supuesta unidad lingüística, como las de la "palabra" gato, la unidad lingüística como tal 
desaparece: solo quedan las relaciones, esto es, la conectividad. Dicho toscamente, lo que parece una unidad lingüística es apenas un nodo en una red de relaciones y esto vale para cualquier significado, lexema, morfema, fonema, rasgo fonológico, etc.

Véase a modo de ejemplo la Figura 3, donde se muestran algunas relaciones en torno a gato y a su aparición en el sistema lingüístico de algún hablante. Con este sistema de notación también se evitan los problemas que surgen cuando se usa una lengua natural como el español para representar una lengua natural como el español. Se ha propuesto que el lenguaje ordinario es lo más apropiado para representar el lenguaje ordinario simplemente porque, después de todo, estamos hablando del lenguaje. Pero esta línea de argumentación nos llevaría a plantear, por ejemplo, que los mapas de rutas tendrían que estar hechos de asfalto o que las piletas deberían hacerse con agua. Más bien, señala Lamb, "necesitamos un sistema de notación tan distinto del lenguaje ordinario como sea posible" ${ }^{1}$ para no confundir el objeto que se describe con los medios de la descripción.

En síntesis, un nodo es lo que es no solo porque ocupa una posición particular en una red de relaciones, sino porque depende de los otros nodos con los cuales está conectado. Así, el "valor" saussuriano toma una dimensión adicional. Un constituyente de la estructura lingüística es "lo que los otros no son". Algo de eso se advierte en la Figura 3, que muestra que los nodos para la "palabra" gato, para el significado FELINO DOMÉSTICO, para el morfema -o, para el fonema /o/, para el rasgo fonológico "dental", etc. no son más que ubicaciones en un sistema de relaciones. Insistamos en ello. Los rótulos FELINO DOMÉSTICO, gato, -o, etc. no son parte de la estructura lingüística, sino que simplemente están ahí como una ayuda para entender el diagrama. La red relacional permite explicar cómo un individuo se representa la información lingüística y cómo esta información constituye el medio para producir y entender las palabras que somos capaces de transcribir en un papel.

Téngase en cuenta que los "triangulitos" desde los cuales salen líneas indican conexiones " $Y$ ", mientras que los "corchetes" de los que también salen líneas marcan conexiones " $O$ ". Para las conexiones " $Y$ " hay una aparición ordenada en nodos como el del lexema gato, conectado hacia abajo con los morfemas gat- $\mathrm{y}-0$. Primero se activa uno $\mathrm{y}$ después el otro, tanto para la producción como para la comprensión. Por otro lado, no hay un orden en nodos como los del fonema /t/, porque los rasgos del fonema (con los que se conecta hacia abajo) aparecen simultáneamente. Por eso las líneas descendentes salen todas desde el mismo punto.

Las líneas que salen y parecen no unirse a nada simplemente indican conexiones existentes que aquí no se representan; por ejemplo, la conexión entre el significado LADRÓN y otros lexemas que no se representan, como caco, ratero, chorro, etc.

La nexión es la unidad fundamental de las redes relacionales, un nodo de la red en virtud del cual se organiza cierta información. Por ejemplo, el 
rótulo para gato, en la Figura 3, aparece a la derecha de lo que podemos llamar la nexión de gato; la figura integrada por la línea junto con el "corchete" de arriba y el "triangulito" de abajo (a cuya izquierda figura el rótulo gato) es en su conjunto la representación de la nexión correspondiente a gato.
Digamos otra vez que los rótulos colocados fuera de las nexiones y las conexiones no son parte de la estructura lingüística, así como los carteles no son parte de una ruta. La información lingüística consta de nexiones y conexiones, no de símbolos. En otras palabras, el sistema interno que hace posible la producción y la comprensión es muy diferente de los símbolos que se manifiestan externamente.

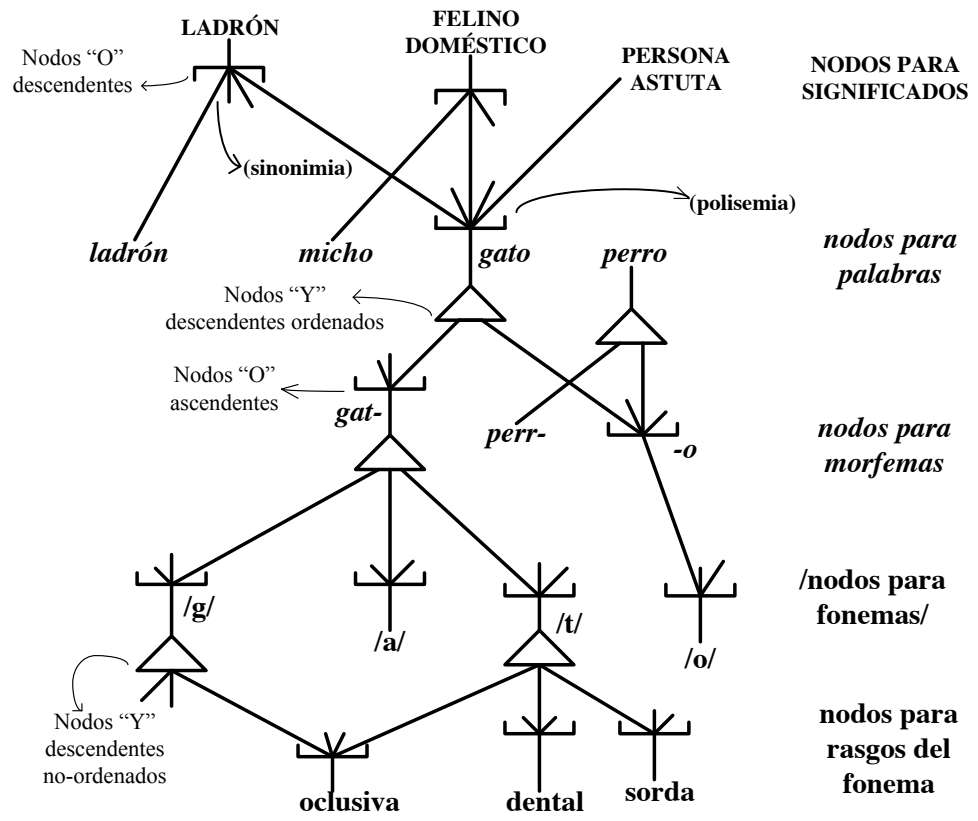

Figura 3. Algunas relaciones en torno al nodo léxico gato y su aparición en el sistema.

En conclusión, la lingüística neurocognitiva es una teoría de redes relacionales que sirve para representar la información lingüística en términos de la conectividad y de las relaciones. Por razones de espacio no es posible explicar todos los detalles de este sistema de notación (que tiene otros tipos de nodos y además otra clase notación, más sutil que la del ejemplo). Sin embargo, resulta posible visualizar algunas de sus ventajas:

- Las redes relacionales dan cuenta de
- La sinonimia consiste en una nexión semántica (UN SIGNIFICADO) que se conecta con más de una nexión léxica ("una palabra"). Por ejemplo, LADRÓN se conecta de forma descendente con ladrón y gato.

- La polisemia consiste en una nexión léxica que se conecta con más de un significado. Por ejemplo, gato se conecta de forma ascendente con FELINO DOMÉSTICO, LADRÓN, PERSONA ASTUTA, etc. fenómenos como la sinonimia y la polisemia: 
- Muestran la continuidad entre los subsistemas lingüísticos, porque permiten ir desde los rasgos del fonema como "oclusivo" hasta los significados como LADRÓN, y viceversa.

- Vinculado con lo anterior, contribuyen a explicar la comprensión y la producción verbal. Quien oye la secuencia gato "va" desde los rasgos del fonema hasta el significado; quien dice gato, "va" desde el significado hasta los rasgos del fonema.

- Explican cómo la información puede llegar a estar localizada y a la vez distribuida en el sistema lingüístico.

- Sirven para entender qué es "el significado de una palabra". Las palabras (o, más técnicamente, las nexiones para los lexemas) no tienen significado, sino que se conectan con significados.

\section{Evidencia neurológica compatible con la lingüística neurocognitiva.}

La teoría propuesta por Lamb se llama neurocognitiva porque por medio de este término (que visiblemente incluye el componente neuro) se busca destacar el siguiente conjunto de factores:

- la teoría busca la plausibilidad neurológica;

- el sistema lingüístico de una persona, gracias al cual habla y entiende el habla de los otros, está en la corteza cerebral de esa persona;

- el objeto de estudio es el (sistema interno de cualquier) individuo concreto;

- es necesario no confundir esta teoría con los enfoques que se llaman "cognitivos" y se basan en la hipótesis de almacenamiento de objetos.
La lingüística neurocognitiva parece plausible en términos neurológicos porque sus hipótesis manifiestan compatibilidad con la evidencia provista por las neurociencias, las cuales muestran que la corteza cerebral es una red de relaciones y que el aprendizaje consiste en el fortalecimiento de las conexiones. Los procesos básicos involucrados en la producción y comprensión de textos funcionan directamente en la red como "patrones de activación que recorren los senderos formados por las líneas y los nodos" ${ }^{\prime 3}$. La información lingüística no se representa en ninguna clase de símbolos, sino que está en las conexiones.

Hay una buena cantidad y variedad de evidencia empírica a favor de las hipótesis de la lingüística neurocognitiva. Sin embargo, no hay evidencia experimental directa debido a varias razones:

- Las neuroimágenes que ofrecen electroencefalogramas o resonancias magnéticas funcionales son muy generales como para obtener información en el nivel microscópico ${ }^{21}$.

- Los experimentos con tejido cerebral de animales vivos no se hacen con humanos por razones éticas muy obvias.

- Los experimentos con tejido cerebral de animales vivos permiten observaciones directas de la percepción visual, auditiva y somato-sensorial ${ }^{22,23,24,}$ 25,26. Pero los monos o los gatos no ejecutan un procesamiento lingüístico comparable al de los seres humanos.

Así y todo, a pesar de estas limitaciones, hay una buena cantidad y variedad de evidencia indirecta a favor de las hipótesis de las redes relacionales. Por ejemplo, Hubel y Wiesel $^{22}$ descubrieron que la 
percepción visual de los gatos y los monos funciona de la forma que lo predice la teoría de redes relacionales y que los nodos de la corteza visual se implementan como columnas corticales. "Los nodos se organizan en una red jerárquica donde cada nivel sucesivo integra los aspectos del nivel siguiente y envía activación a los niveles más altos”³.

El eminente neurocientífico Vernon Mountcastle ha señalado que "la minicolumna cortical es la unidad de procesamiento más pequeña de la corteza cerebral" $^{26}$ y también propone que "todos los estudios celulares efectuados con la corteza auditiva de gatos y monos proveen evidencia directa de la organización en columnas de la corteza cerebral”26.

En efecto, la corteza cerebral se organiza como un mosaico de columnas corticales. Cada columna cortical, es decir, cada unidad básica de procesamiento en la corteza cerebral consiste en un manojo de varias minicolumnas cuyo tamaño está entre el de la minicolumna y la maxicolumna (un racimo de unas 100 minicolumnas). Téngase en cuenta que el diámetro de una minicolumna cortical tiene alrededor de 50 micrones (y que un micrón es la milésima parte de un milímetro).

Por ejemplo, la especificidad de modalidad es una característica definitoria de la corteza somatosensorial. Un experimento de regeneración de nervios en un mono brinda evidencia a favor de la organización en columnas de la corteza somatosensorial y permite estimar que la minicolumna cortical es el elemento identificable más pequeño. Un microelectrodo de registro se pasa de forma casi paralela a la superficie pial de la corteza somatosensorial a través de una región de neuronas con las mismas propiedades de modalidad. Las neuronas en las minicolumnas adyacentes se relacionan con campos receptivos periféricos adyacentes y superpuestos. El resultado es que las transiciones entre minicolumnas pasan inadvertidas. En una etapa siguiente del experimento, los resultados obtenidos con el mismo animal después del corte y la sutura del nervio medial contralateral muestran una desviación de los haces de fibras nerviosas en regeneración que en esta etapa enervan la piel sin pelo de la mano. Movimientos repentinos de los lugares de los campos receptivos se dan en intervalos de 50-60 micrones. Este resultado pone de manifiesto las minicolumnas y su tamaño transverso ${ }^{26}$.

Ahora bien, la percepción del habla es un proceso de alto nivel en la corteza del cerebro humano. Por ello la lingüística neurocognitiva propone la siguiente extrapolación: cada nexión del sistema lingüístico de una persona se implementa en el cerebro de esa persona como una columna cortical. Cada nexión/columna cortical tiene una función altamente específica, por ejemplo, habrá una nexión/columna cortical que permita el procesamiento de lo que externamente podemos representar como la palabra gato: debe haber grupos de neuronas encargadas del procesamiento de la información léxica. Considérese la evidencia de cómo la circunvolución angular participa en el procesamiento léxico: personas con daños en esta área sufren una manifiesta pérdida de muchas conexiones léxicas. El síntoma más notable es la anomia, esto es, el impedimento para nombrar. Los pacientes que sufren anomia no pueden nombrar objetos ni señalar un objeto al oír su nombre, aun 
cuando el reconocimiento fonológico no se ha visto dañado ${ }^{27}$.

Llegamos aquí a un punto fundamental: la teoría de redes relacionales establece, antes de evaluar su implementación neurológica, que los nodos y las conexiones tienen las siguientes características ${ }^{3}$ :

a) Las conexiones tienen fuerza y grados de activación variables.

b) Las conexiones se fortalecen por medio del uso exitoso.

c) Las conexiones con una fuerza dada tienen grados de activación variable.

d) Las nexiones tienen umbrales de activación variables.

e) El umbral de una nexión puede variar a lo largo del tiempo.

f) Las conexiones son de dos tipos: de excitación e inhibitorias.

g) Las conexiones de excitación son bidireccionales, se realimentan prospectiva y retrospectivamente.

h) Las conexiones de excitación pueden ser locales o distantes.

i) Las conexiones inhibitorias son únicamente locales.

j) Las conexiones inhibitorias se conectan a un nodo o a una línea.

k) En las etapas tempranas (anteriores al aprendizaje propiamente dicho) la mayor parte de las conexiones no está aún establecida (está "latente").

I) Algunas nexiones tienen que incluir un elemento de espera para permitir la aparición ordenada de los elementos de una secuencia, por ejemplo las sílabas de una palabra.
Las propiedades de la red (a) - (I) están determinadas por consideraciones lingüísticas, no neurológicas: se necesitan para caracterizar los datos y los procesos lingüísticos, aún los del aprendizaje. Por ello, las características enunciadas son predicciones de la teoría lingüística acerca de qué debe haber en el cerebro en el caso de que la teoría sea verdadera. En otras palabras, la teoría de redes relacionales presenta la hipótesis de que las nexiones y las conexiones tienen un conjunto de características $n$ y confirma que esas características $n$ son también las características de las columnas corticales y las conexiones neuronales. En efecto, la evidencia neurológica muestra que las columnas corticales y sus interconexiones tienen todas y cada una de las propiedades (a) - (I). Por ejemplo, el elemento de espera consignado en la propiedad (I) se implementa por medio de fibras del axón que se ramifican desde los axones de las neuronas piramidales dentro de una columna y se conectan verticalmente con otras células de la columna. Desde la capa VI de la corteza estas células se proyectan de forma ascendente y desde las capas más altas de forma descendente. Esta activación circulante entre las células piramidales de la columna mantiene viva la activación hasta que es apagada por las neuronas inhibitorias con axones extendidos verticalmente dentro de la misma columna: estas neuronas inhibitorias son las células-canastas dobles ${ }^{3}$.

Por otra parte, el "test de la capacidad" permite estimar los números de nexiones que necesita el modelo de redes y los compara con los números de columnas corticales que puede haber en el cerebro de un individuo. Parece que hay una disponibilidad 
muy grande de nexiones/columnas corticales en los lugares adecuados como para que le resulten suficientes a una persona lo largo de toda su vida. A partir de los datos provistos por la afasiología, es razonable mantener la hipótesis de que el área de la percepción fonológica se sitúa en el área de Wernicke. Esta área requiere suficientes nexiones como para representar todas las unidades fonológicas que puede llegar a necesitar una persona en toda su vida, lo que incluye fonemas, sílabas, palabras fonológicas, frases fonológicas fijas, y en tantas lenguas diferentes como esa persona tenga la capacidad de aprender a hablar con fluidez. Una estimación generosa sería 50.000 nexiones/columnas por lengua. Si multiplicamos ese número por 20 (para el caso de un políglota fenomenal), se requeriría 1.000.000 de nexiones.

Para contrastar esta hipótesis se hace necesario estimar el número de columnas corticales en el área de Wernicke. En un individuo típico, esta área incluye la parte posterior de la circunvolución temporal superior $y$ se extiende también hacia la circunvolución temporal media (la sección posterior del área 22 de Brodmann). La superficie aproximada en un individuo típico es de entre 15 y $20 \mathrm{~cm}^{2}$. La densidad de neuronas es de 80.000 a 100.000 por milímetro cuadrado de superficie cortical, y cada columna cortical está integrada por unas 100 neuronas. Estos números gruesos dan un rango que va de 1.200 .000 columnas (en un área de $15 \mathrm{~cm}^{2}$ con 80.000 columnas por $\mathrm{cm}^{2}$ ) a 2.000 .000 de columnas (en un área de $20 \mathrm{~cm}^{2}$ con 100.000 columnas por $\mathrm{cm}^{2}$ ). Digamos que en el área de Wernicke puede haber de 1,2 a 2 millones de nexiones/columnas corticales, unas cuantas más nexiones latentes que el millón que necesitaría un políglota extraordinario y un número inmensamente mayor que el de las nexiones/columnas que necesitaría un hablante monolingüe o bilingüe "normal". La hipótesis de la disponibilidad cuantitativa estaría así confirmada.

Sobre la base de las consideraciones previas puede ahora proponerse el argumento de la plausibilidad neurológica de las redes relacionales:

- Las nexiones de las redes relacionales se implementan como columnas corticales.

- Las conexiones de las redes relacionales se implementan como fibras y conexiones neuronales.

- Las columnas corticales y las fibras neuronales integran conexiones corticales reales.

- Por lo tanto, las redes relacionales representan conexiones corticales reales.

En la parte correspondiente a la discusión se intentará mostrar cómo esta teoría neurológicamente plausible nos ayuda a mostrar cómo se representa la información fonológica en el sistema lingüístico del cerebro.

\section{Discusión}

En términos neuroanatómicos, las fibras del fascículo arqueado son los axones de las neuronas piramidales provenientes en centenas de miles desde las columnas distribuidas en el área de Wernicke. No se sabe aún si el fascículo arqueado tiene fibras "bidireccionales", pero sí se sabe que las conexiones corticocorticales, cuya función es relacionar las áreas asociativas con otras áreas de la corteza, son "recíprocas". Cabe esperar entonces que las fibras del fascículo arqueado también manifiesten esta bidireccionalidad. 
La plausibilidad operativa que buscan las hipótesis de la lingüística neurocognitiva también sería consistente con el hecho de que somos capaces de decir (y monitorear) alrededor de dos palabras por segundo. Este hecho también podría explicarse en virtud de la conexión de los dos subsistemas fonológicos y del (presumible) carácter recíproco de sus conexiones. A continuación se buscará mostrar de qué manera puede representarse la conexión entre los nodos de los dos subsistemas fonológicos.

La lingüística neurocognitiva de Lamb ha desarrollado un sistema de notación que permite representar la información lingüística en términos de la conectividad. Como se ha dicho, las fuentes de inspiración para este sistema de notación están en las obras de Saussure ${ }^{17}$, Hjelmslev ${ }^{18}$ y Halliday ${ }^{19}$. En este sentido, el lingüista danés Louis Hjelmslev había hecho explícita la idea de que el sistema lingüístico es un complejo sistema donde no hay unidades estáticas:

"The recognition [...] that a totality does not consist of things but of relationships, and that not substance but only its internal and external relationships have scientific existence [...] may be new in linguistic science. The postulation of objects as something different from the terms of relationships is a superfluous axiom and consequently a metaphysical hypothesis from which linguistic science will have to be freed" ${ }^{18}$.

En efecto, un constituyente del sistema lingüístico es lo que es no solo porque ocupa una posición particular en una red de relaciones, sino porque depende de los otros nodos con los cuales está conectado. Así, el "valor" saussuriano toma una dimensión adicional: un nodo lingüístico es "lo que los otros no son".

Debe destacarse que las inscripciones que aparecerán en las figuras junto a nodos y conexiones no son parte de la red relacional. La red consta solo de nodos y conexiones. Los rótulos sirven únicamente para entender el diagrama.

Desde luego, el sistema de notación de las redes relacionales tiene su complejidad. Las explicaciones que siguen acaso sirvan para entender mejor la información que aquí se representará:

- Como ya se ha dicho, la red consta de nodos y relaciones. Los rótulos para significados, palabras o fonemas no son parte de la red, sino rótulos que facilitan la comprensión de la red.

- La producción lingüística se representa “de arriba hacia abajo", es decir, desde los significados (con mayúsculas), pasando por el nivel léxicogramatical (lexemas y morfemas, con cursiva) hasta el nivel fonológico (sílabas, fonemas, rasgos del fonema).

- La comprensión lingüística se representa "de abajo hacia arriba", es decir, desde la fonología hasta la semántica.

Lamb también sugiere que las redes relacionales tienen plausibilidad neurológica ${ }^{3}$ porque los nodos y las conexiones (como los que se representarán en las figuras) se implementan a nivel neurológico como columnas corticales y conexiones neuronales respectivamente.

En efecto, las propiedades de los nodos de la red coinciden con las propiedades de las columnas 
corticales reales, mientras que las propiedades de las conexiones coinciden con las de las conexiones neuronales. Por ejemplo, los nodos de las redes relacionales y las columnas corticales tienen umbrales de activación; tanto los umbrales de un nodo como los de una columna cortical pueden variar a lo largo del tiempo. De un modo análogo, las conexiones de las redes relacionales y las conexiones neuronales tienen fuerzas variables y se fortalecen por medio del uso exitoso, lo que da cuenta del proceso de aprendizaje ${ }^{3}$.

A continuación se tratará de ilustrar la representación neurocognitiva de la información lingüística en torno a la palabra monosilábica castellana mar, con especial énfasis en la fonología y referencias más generales a la léxico-gramática y a la semántica. De acuerdo con los lineamientos de la "notación fina" de las redes relacionales, la Figura 4 representa el reconocimiento del fonema $/ \mathrm{m} /$ :

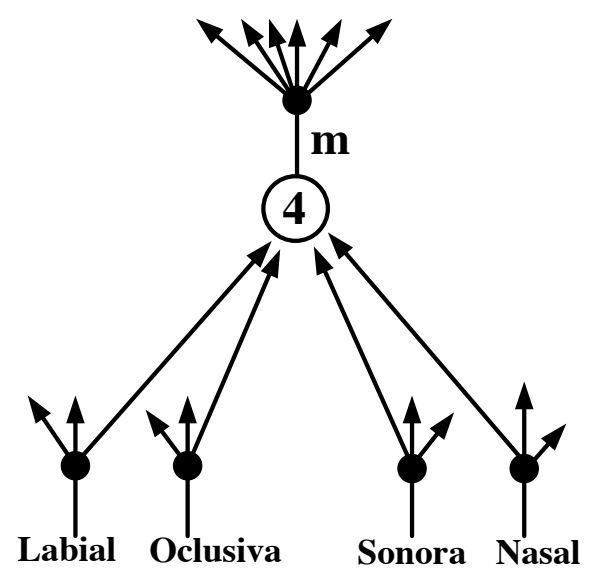

Figura 4. Reconocimiento del fonema $/ \mathrm{m} /$.

- Los cuatro nodos para los rasgos del fonema $/ \mathrm{m} /$ se tienen que activar de forma simultánea para que se active el nodo correspondiente a $/ \mathrm{m} /$.
- El círculo con el número "4" indica que precisamente deben llegar las cuatro activaciones para que el nodo de $/ \mathrm{m} /$ se active.

- Las flechas están "con la punta para arriba" porque aquí se está dando cuenta del proceso perceptivo el cual, en términos abstractos, va "de abajo hacia arriba".

- Los círculos negros para los nodos de los rasgos fonológicos ("fonones" es el neologismo de la teoría para estos nodos) y para el nodo del fonema /m/ (la "fononexión" para /m/) marcan el límite superior interno del nodo.

- De esos círculos negros salen flechas hacia arriba porque cada nodo, después de ser activado (en este caso en el círculo con el "4"), envía activación hacia arriba.

Los rótulos para los rasgos fonológicos del reconocimiento de /m/ no se corresponden directamente con la fonética acústica sino que expresan rasgos articulatorios: labial, oclusiva, sonora, nasal. Esto no es un problema para las redes relacionales neurocognitivas, porque los nodos de la Figura 4 son los que participan de cualquier forma en el reconocimiento de $/ \mathrm{m} /$, independientemente de cómo se los llame. Recordemos, una vez más, que los rótulos no son parte de la estructura lingüística. Estrictamente, los nodos para los rasgos fonológicos de la Figura 4 tienen que interpretarse como los nodos de los rasgos perceptivos que, a su vez, se conectan con los rasgos articulatorios por medio del fascículo arqueado (Véase más adelante la Figura 14). Los círculos negros representan el límite interno superior del nodo y decíamos antes que de ellos 
salen líneas que van a activar otros nodos. La Figura 5 representa este fenómeno: los nodos correspondientes a $/ \mathrm{m} / \mathrm{y} / \mathrm{a} /$ activan el nodo de la demisílaba /ma/.

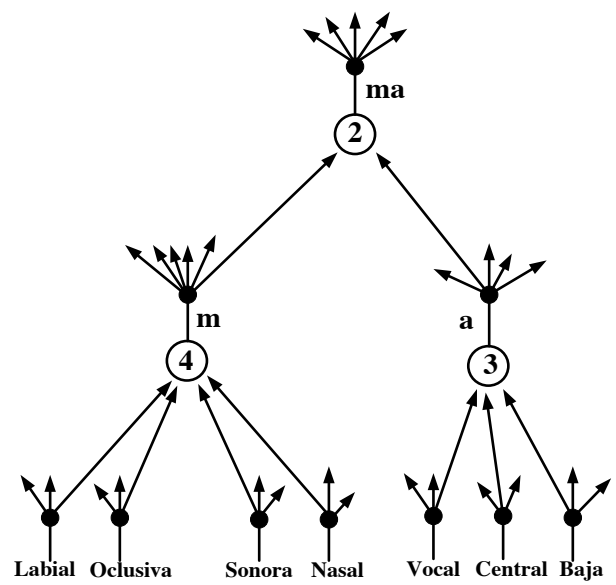

Figura 5. Reconocimiento de la demisílaba /ma/.

Lamb sugiere la hipótesis de que en el reconocimiento fonológico no solo percibimos los fonemas y las sílabas, sino también las partes de una sílaba, que él Ilama "demisílabas". La Figura 5 representa cómo se percibe la demisílaba /ma/ y la Figura 6 representa cómo se perciben las demisílabas /ma/ y /ar/, antes de percibir la sílaba completa /mar/.

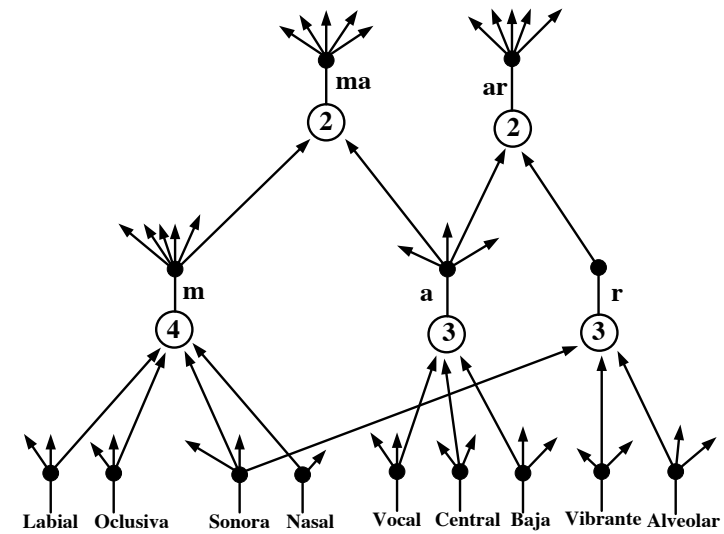

Figura 6. Reconocimiento de las demisílabas /ma/ y /ar/.
Es pertinente ahora presentar tres aclaraciones:

- Los números que aparecen dentro de los círculos especifican el valor del umbral, es decir, cuántas líneas/conexiones entrantes tienen que activarse para que el nodo en cuestión se active. Por ejemplo, el nodo para la demisílaba /ar/ requiere la activación entrante que proviene del nodo para /a/ y el nodo para /r/. Por eso su valor es " 2 " y se activa cuando llegan esas dos líneas.

- $\quad$ La Figura 4 representa un nodo que se activa de forma no-ordenada, es decir, en simultáneo: el nodo umbral con valor " 4 " se activa porque todas las líneas entrantes llegan al mismo tiempo. Esto es así porque los rasgos de un fonema aparecen todos juntos, al mismo tiempo, y no en una secuencia.

- $\quad$ Pero las Figuras 5 y 6 representan nodos que se activan de forma ordenada, es decir, secuencial. Evidentemente, para la activación del nodo con valor "2" correspondiente a la demisílaba /ma/, primero tiene que activarse el nodo para /m/ y después de esto tiene que activarse el nodo para /a/.

El problema de la representación de los nodos ordenados es uno de los desafíos más apasionantes de la teoría. Lamb le dedica al asunto varios pasajes de su libro Pathways of the Brain, donde sugiere al menos dos hipótesis alternativas para explicar el funcionamiento del constituyente de espera en las secuencias ordenadas: la retroalimentación y la sincronización de intervalo fijo ${ }^{1}$.

En el sistema de notación "compacto" presentado anteriormente (también llamado "abstracto") hay una convención para representar las secuencias ordenadas de un modo que queda claro 
que la activación se da de forma secuencial1. Ocurre que los nodos de la notación abstracta/compacta son bidireccionales $y$ en las figuras de este trabajo estamos buscando una representación neurológicamente plausible, que tenga en cuenta los siguientes hechos: que el reconocimiento va en dirección ascendente; que la producción va en dirección descendente; y que el reconocimiento (ascendente) y la producción (descendente) están conectados a través del fascículo arqueado. Para llegar a dar cuenta de los tres hechos anteriores se requiere la notación fina.

Con el fin de mostrar que la activación de secuencias ordenadas se da de forma (obviamente) ordenada, se utilizará una convención ad hoc: en las figuras que siguen incorporamos un rótulo ordinal en cursiva junto a cada nodo que se activa de forma ordenada. Obsérvese entonces en la Figura 7, cómo se representa el reconocimiento de la sílaba /mar/.

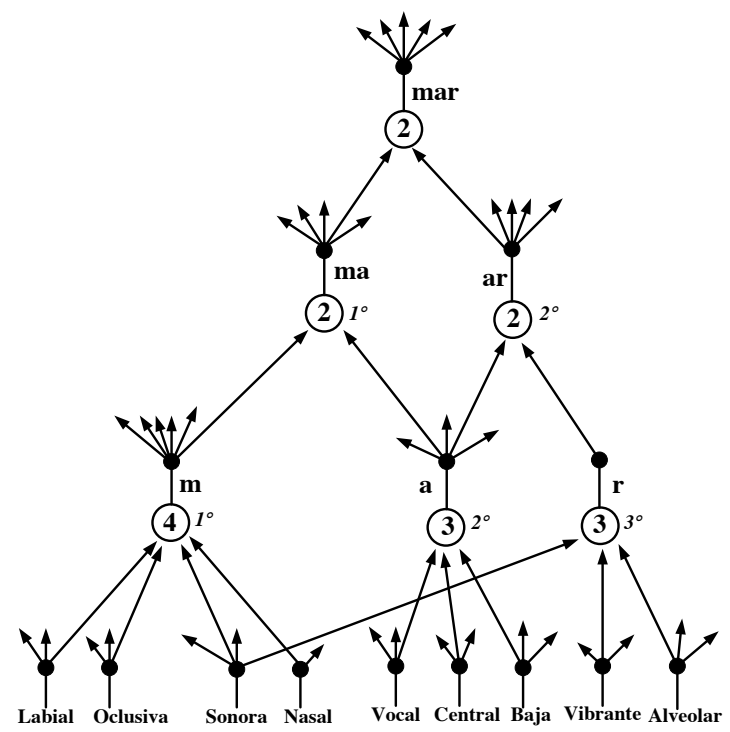

Figura 7. Reconocimiento de la sílaba /mar/.
Según Lamb ${ }^{1}$, las redes relacionales neurocognitivas son plausibles en términos del funcionamiento en tiempo real (plausibilidad operativa), del proceso de aprendizaje (plausibilidad de desarrollo) y de la evidencia neurológica (plausibilidad neurológica). Sin embargo, las redes neurocognitivas son también extraordinariamente complejas y por ello quedan todavía unos cuantos años de investigación para empezar a entender las precisiones sobre su estructura y su funcionamiento. Además de los descubrimientos pertinentes de las neurociencias, la otra gran ruta de investigación en este sentido es la modelización computacional. Por ello la convención ad hoc del ordinal en cursiva no es ni de cerca una contribución para el tratamiento de las secuencias ordenadas, sino una convención útil a los efectos de lo que se está representando en las figuras. Por otro lado, el objetivo de empezar a entender cómo se implementan las secuencias ordenadas excede la acotada propuesta de este trabajo (aunque desde luego guarda relación con ella).

Una vez que tomamos conciencia del problema del orden, podemos considerar que la fonología se conecta con la información léxicogramatical. Así, la Figura 8 incorpora la representación del nodo léxico para mar, una palabra monosilábica y mono-morfemática. 


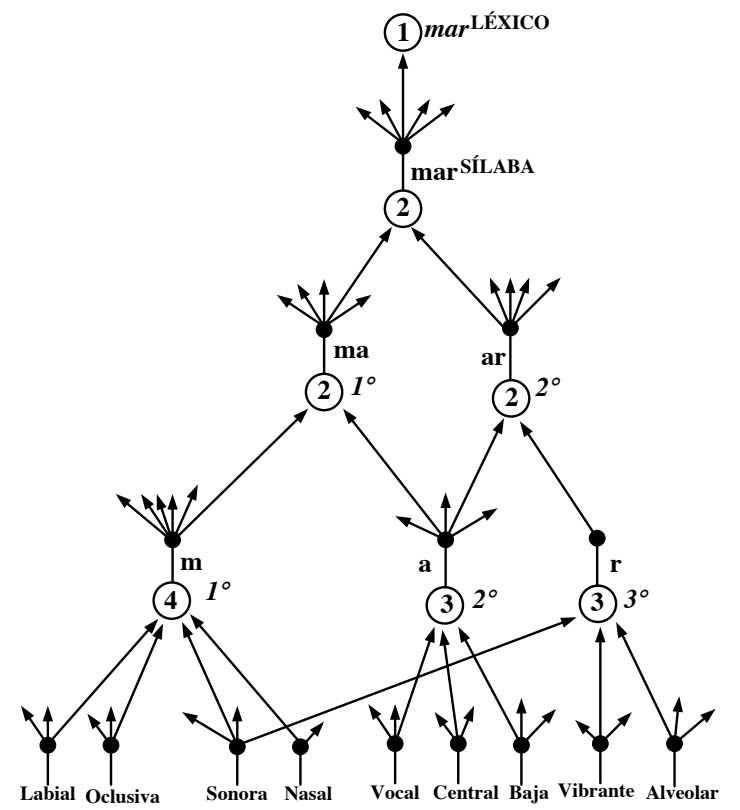

Figura 8. Activación del nodo léxico para mar.

Por su parte, la Figura 9 presenta las activaciones de las líneas que conectan el nodo léxico para mar con diferentes significados posibles dentro del sistema de conocimiento de un individuo que maneja esa palabra. Las líneas que salen del nodo léxico para mar se conectan de forma ascendente con los nodos semánticos, por ejemplo los que se corresponden con MAR [OCÉANO], ESPACIO GRANDE, MUCHA CANTIDAD, etc. (los rótulos para los nodos semánticos se escriben con mayúsculas). La conexión entre el nodo léxico y los nodos semánticos puede representarse con un nodo " $\mathrm{O}$ " ascendente de la notación compacta (un corchetito) porque este tipo de notación presenta nodos y conexiones bidireccionales, $y$, en efecto, las activaciones de la léxico-gramática y la semántica no van en un solo sentido como las activaciones de los sistemas fonológicos de reconocimiento y producción.

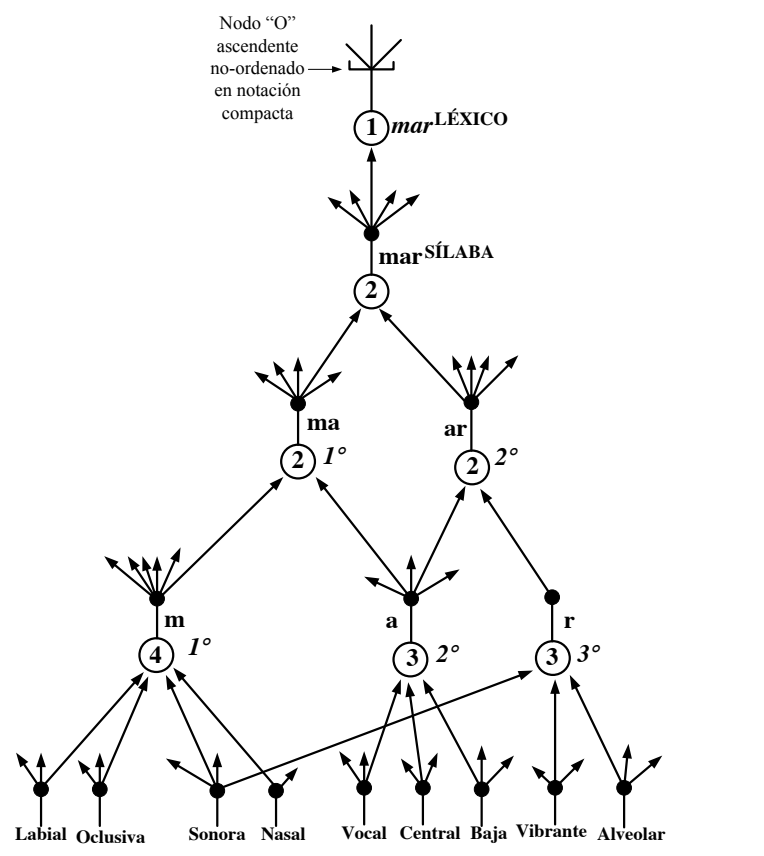

Figura 9. El nodo léxico para mar con los nodos semánticos.

La Figura 10 incorpora la representación del nodo semántico para MAR. El semicírculo representa un nodo umbral. Este tipo de nodo no es un nodo " $Y$ " (que recibe la activación de todas las líneas entrantes) ni un nodo " $O$ " (que tiene que activar una de las líneas entrantes). El nodo umbral para MAR tiene que recibir la activación de algunas de las muchísimas conexiones entrantes que tiene este nodo, como otros conceptos (AGUA, SALADO, INMENSO) e incluso las conexiones provenientes de nodos de sistemas cognitivos como la visión (la imagen visual del mar), el sistema somato-sensorial (la representación del contacto físico con el mar) o la audición (la imagen auditiva del sonido del mar). 


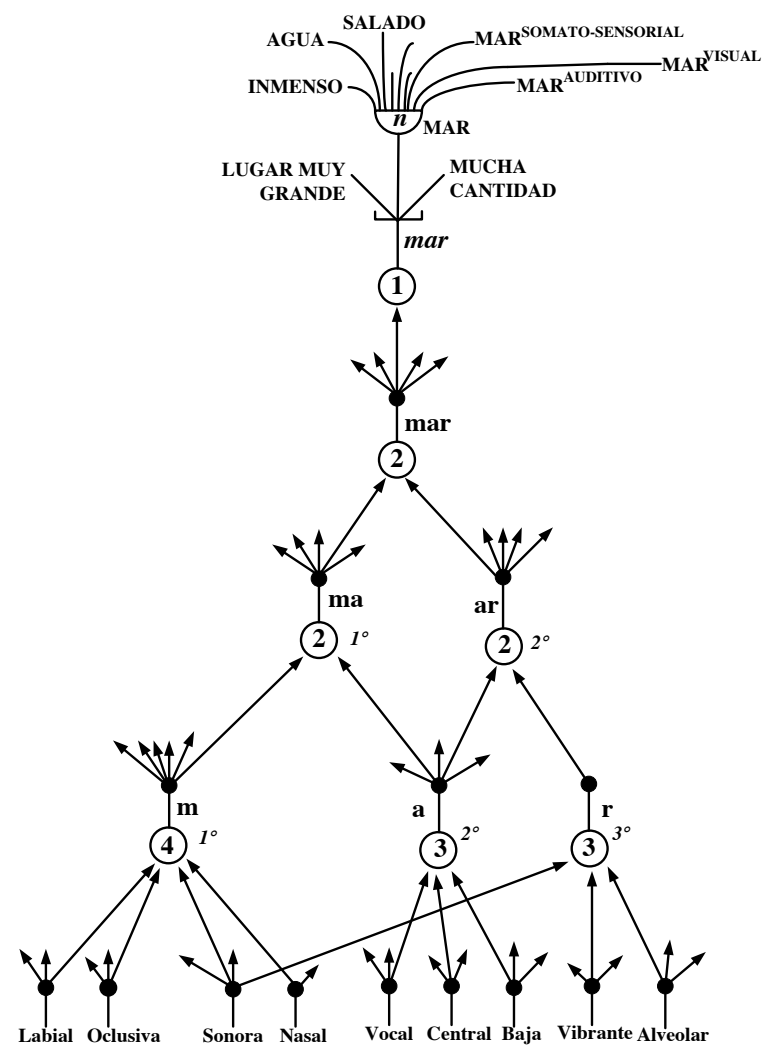

Figura 10. El nodo semántico para MAR (con un nodo umbral de valor indefinido $n$ ).

Ahora bien, las Figuras 4 a 10 representan senderos que van desde el reconocimiento fonológico hasta la semántica, vía el léxico. Queda todavía la representación de los senderos de la producción fonológica, que constituye un subsistema lingüístico diferente del reconocimiento fonológico. La Figura 11 describe la producción fonológica a partir de la sílaba /mar/. Los círculos con el número "1" indican que estamos ante nodos "O": los nodos para los fonemas como /m/ se conectan de forma ascendente con muchos otros nodos de sílabas, pero solo un nodo de más arriba es el que de hecho produce la activación. Debe señalarse también que la activación es ordenada: primero se activa el nodo de /m/, luego el de /a/, y por último el nodo para /r/. No se representan demisílabas porque estas solo forman parte de la percepción.

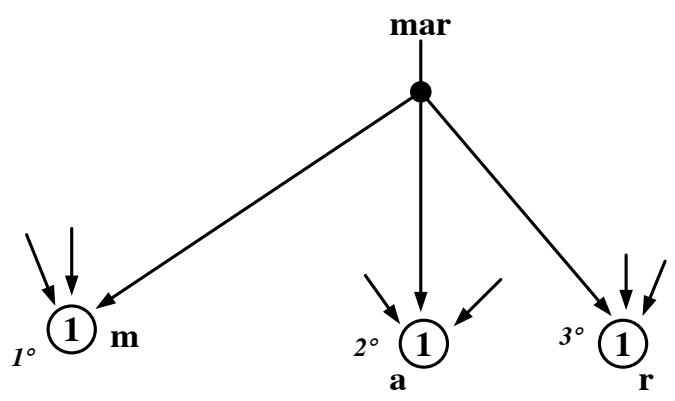

Figura 11. Producción fonológica de la sílaba /mar/.

Luego, la Figura 12 incluye la activación de los nodos para los rasgos de los fonemas, los cuales a su vez, enviarán activación a los nodos de la producción articulatoria, área responsable de la emisión concreta y material de la palabra mar. Está claro que en los nodos para los rasgos no se indica ningún ordinal porque la activación es no ordenada.

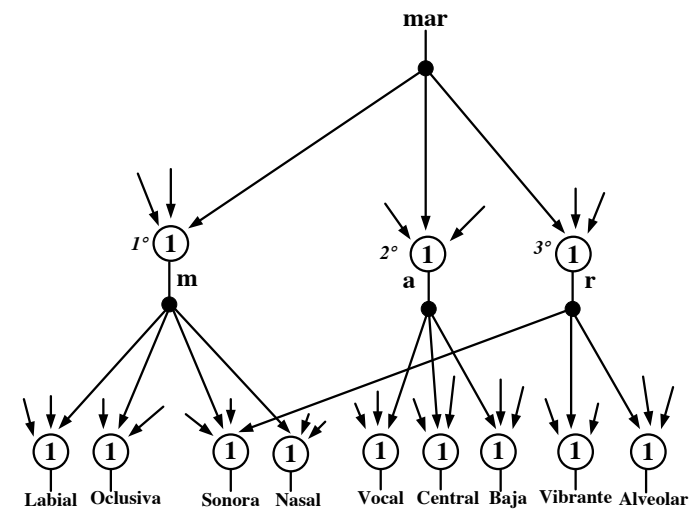

Figura 12. Producción fonológica de /mar/, con la activación de los rasgos del fonema.

A continuación, la Figura 13 reúne la información presentada en dos de los diagrama anteriores, el de la Figura 10 (Reconocimiento fonológico de /mar/, nodo léxico para mar y nodo semántico para MAR, con un nodo umbral de valor 
indefinido $n$ ) y el de la Figura 12 (Producción fonológica de la sílaba /mar/).

Se ubica al nodo léxico para mar en una localización posterior porque los sustantivos se representan mayormente en zonas posteriores (temporales y parietales) y los verbos en zonas frontales (lóbulo frontal). En principio, esta hipótesis es plausible gracias a los estudios de afasiología: los pacientes con daño frontal manifiestan una tendencia a tener inconvenientes con los verbos, mientras que los pacientes con daños posteriores manifiestan la tendencia a tener más problemas con el uso de sustantivos ${ }^{28,29,30,31,32}$.

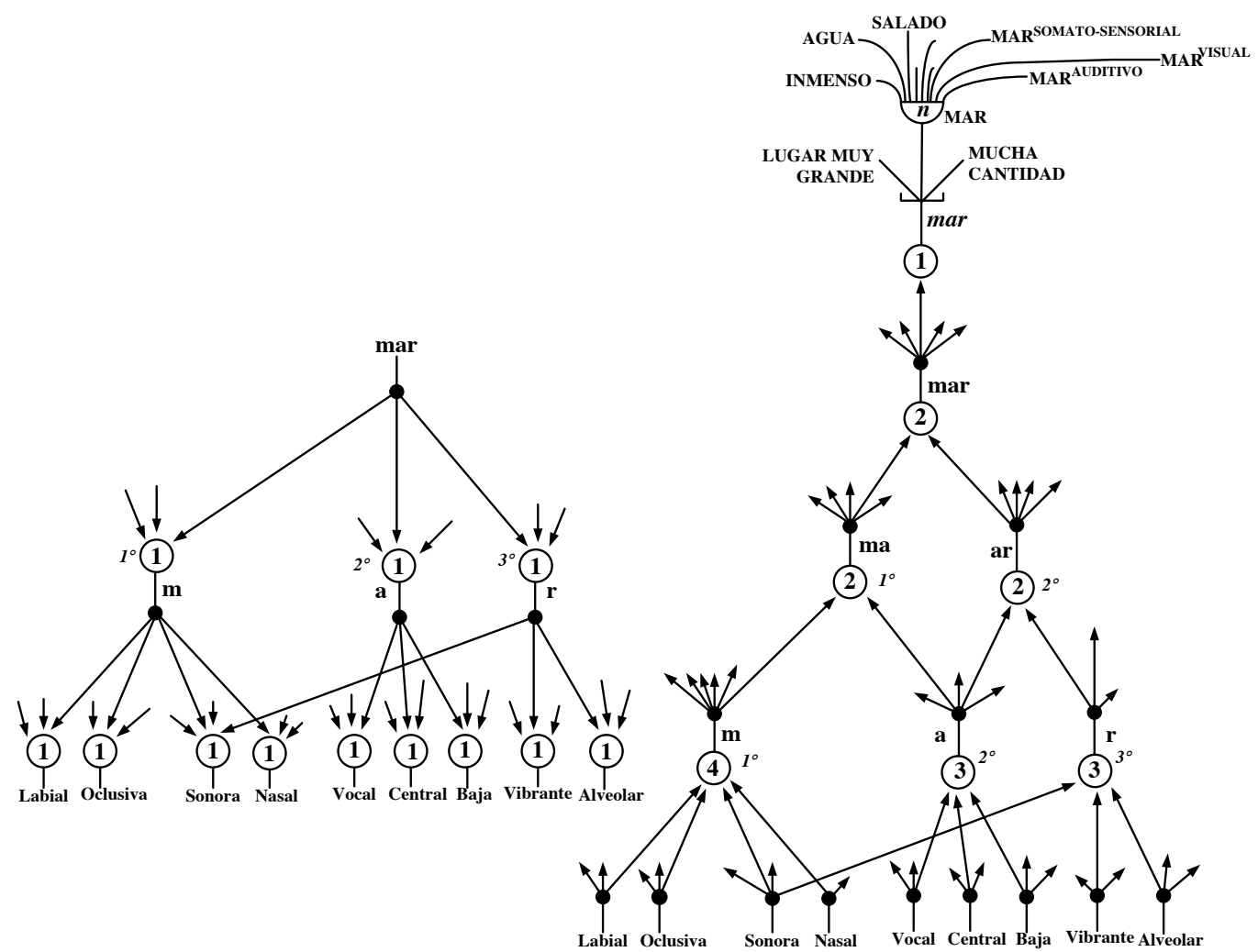

Figura 13. Reunión de la producción fonológica (Figura 11) con el reconocimiento fonológico, el nodo léxico para mar y el nodo semántico para MAR (los tres últimos, en la Figura 10).

Por último, la Figura 14 intenta representar que cada nodo del sistema fonológico de reconocimiento (además de conectarse localmente con otros nodos) se conecta con su nodo correspondiente en el sistema de producción fonológica a través del fascículo arqueado. La Figura 14 conecta, por ejemplo, el nodo para la sílaba /mar/ y el nodo para el fonema /m/ de la zona de reconocimiento fonológico con el nodo para la sílaba /mar/ y el nodo para el fonema /m/ de la zona de producción fonológica, respectivamente. De un modo análogo, los nodos de los rasgos perceptivos en el reconocimiento fonológico se conectan con los nodos de los rasgos articulatorios la producción fonológica. 


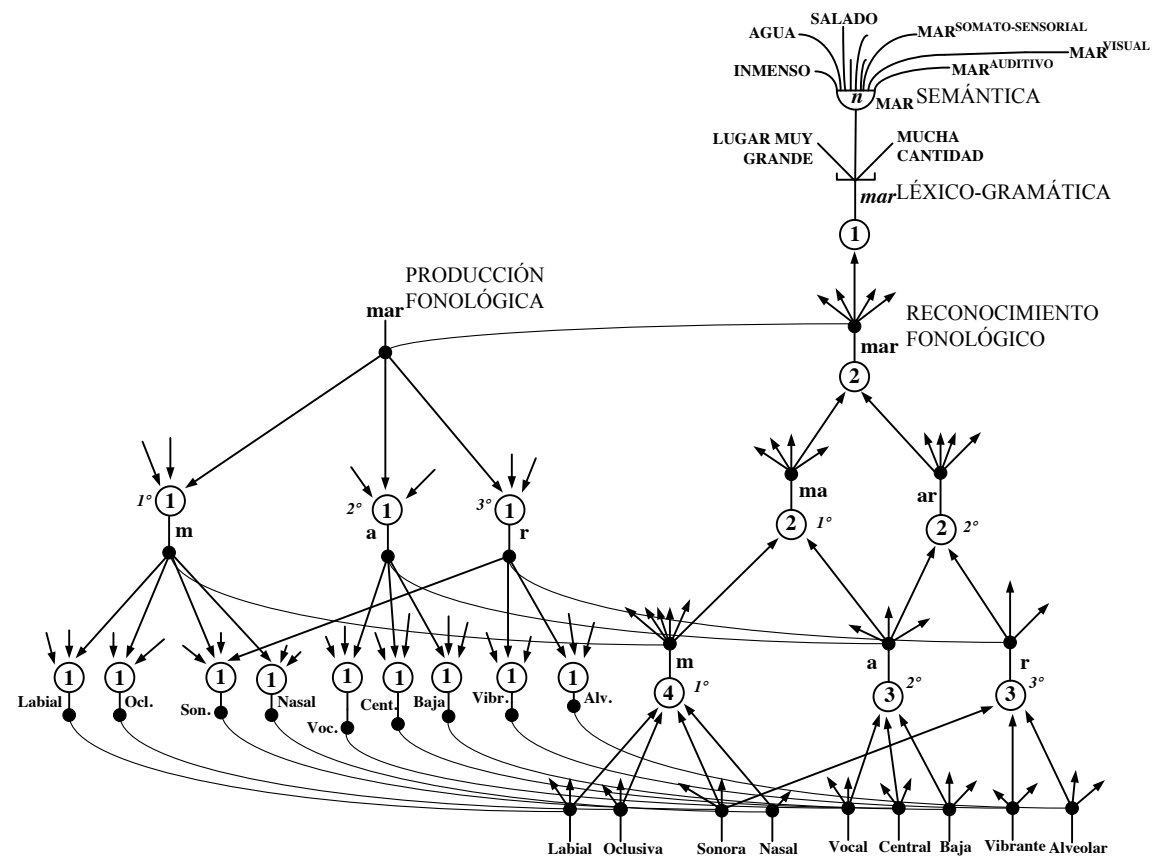

Figura 14. Incorporación de conexiones del fascículo arqueado: los nodos del sistema de reconocimiento se conectan con su nodo correspondiente en el sistema de producción, y viceversa.

En conclusión, las redes relacionales neurocognitivas contribuyen, en gran medida, a entender estas dos cuestiones fundamentales para la lingüística, tanto en su dimensión biológica como en su dimensión teórica:

- $\quad$ Cómo se conecta la información del sistema fonológico de reconocimiento y la información del sistema fonológico de producción por medio del fascículo arqueado.

- $\quad$ Cómo se conecta la información de los dos sistemas fonológicos con el sistema léxico-gramatical y el sistema semántico.

Todo esto contribuye a reforzar la hipótesis neurocognitiva según la cual "eso que llamamos lenguaje" es una complejísima interacción de subsistemas a los que nos gusta ver como una unidad fundamentalmente porque nos hemos acostumbrado a ello o porque nos resulta cómodo. 


\section{Referencias}

1. Lamb, S. M. (1999) Pathways of the Brain. The Neurocognitive Basis of Language. Amsterdam: John Benjamins. [Trad. esp. Senderos del cerebro. La base neurocognitiva del lenguaje, Mar del Plata: EUDEM, 2011].

2. Lamb, S. M. (2004) Language and reality. London: Continuum.

3. Lamb, S. M. (2005) When Experiments are Unfeasible, You Have to Think Harder. Language and the Human Sciences, 1, 151-178.

4. Lamb, S. M. (2006) Being Realistic, Being Scientific. In S. J. Hwang, W. J. Sullivan and A. R. Lommel (Eds.), LACUS Forum 32: Networks. Houston, pp. 201-209.

5. Lamb, S. M. (2013) Systemic networks, relational networks, and choice". In L. Fontaine, T. Bartlett and G. O'Grady (Eds.) Choice: critical considerations in Systemic Functional Linguistics. Cambridge, Cambridge University Press, pp. 137-160.

6. Lamb, S. M. (2001) Questions of Evidence in Neurocognitive Linguistics. In J. Webster (Ed.), Language and reality. London: Continuum, pp. 324-351.

7. Goodglass, D. (1993) Understanding Aphasia. San Diego: Academic Press.

8. Lamb, S. M. (2002) On the Perception of Speech. In J. Webster (Ed.), Language \& reality. London: Continuum, pp. 352-357.

9. Blumstein, S. E. (1995) The neurobiology of the sound structure of language. In M. S. Gazzaniga (Ed.), The Cognitive Neurosciences. Cambridge, Mass: MIT Press, pp. 915-929.

10. Pinker, S. (1994) The Language Instinct. New York: Morrow.

11. Wernicke, C. (1885) Recent works on aphasia. In G. Eggert, Wernicke's Works on Aphasia. La Haya: Mouton, pp. 173-205.

12. Quine, W. (1953) Dos dogmas del empirismo. En L. M. Valdés Villanueva (Comp.), La búsqueda del significado. Madrid: Tecnos, pp. 247-270.
13. Geschwind, N. (1964) The development of the brain and the evolution of language, Report of Fifteenth Annual (First International) Round Table Meeting on Linguistics and Language Studies, ed. By C.I.J.M. Stuart, 155-169. Monograph Series on Languages and Linguistics, № 17. Washington, D.C.: Georgetown University School of Languages and Linguistics.

14. Geschwind, N. (1965) Disconnection syndromes in animals and man. Brain, 88, pp. 585-644.

15. Sweet, H. (1891) A New English grammar (I): Introduction, phonology, accidence. Oxford, Clarendon Press.

16. Badouin de Courtenay, J. (1897) Statements of linguistic principles. In E. Stankiewicz, A Badouin de Courtenay Anthology. Bloomington: Indiana University Press, pp. 213-215.

17. Saussure, F. (1916) Curso de Lingüística General. Buenos Aires, Losada.

18. Hjelmslev, L. (1943/1961). Prolegomena to a Theory of Language. [Trans. english F.J. Whitfield, second edition. Madison: University of Wisconsin Press].

19. Halliday, M. A. K. $(1967,1968)$ Notes on transitivity and theme in English. Journal of Linguistics, I: 3 (1), pp. $37-$ 81; II: 3 (2), pp. 199-244; III: 4 (1), pp. 179-215.

20. Halliday, M. A. K y C. M. Matthiessen (2004) An Introduction to Functional Grammar. London: Arnold.

21. Cherchi, M. (2000) Investigation of the Brain under Non-pathological Conditions, Section 3 of Challenges in the Investigation of Cerebral Function: Neuroanatomical Substrates of Language Processing. LINCOM Europa, 2000, pp. 19-28.

22. Hubel, D. \& T. N. Wiesel (1962) Receptive fields, binocular interaction and functional architecture in the cat's visual cortex. Journal of Physiology, 160, pp. 10654.

23. Hubel, D. \& T. N. Wiesel (1968) Receptive fields and functional architecture of monkey striate cortex. Journal of Physiology, 195, pp. 215-243. 
24. Hubel, D. \& T. N. Wiesel (1977) Functional architecture of macaque monkey cortex. Proceedings of the Royal Society of London, 198, pp. 1-559.

25. Mountcastle, V. (1997) The columnar organization of the neocortex. Brain, 120, pp. 701-722.

26. Mountcastle, V. (1998) Perceptual Neuroscience: The Cerebral Cortex. Cambridge: Harvard University Press.

27. Benson, D. F. \& A. Ardila (1996) Aphasia: A Clinical Perspective. Nueva York \& Oxford: Oxford University Press.

28. McCarthy, F. \& E. Warrington (1985) Category specificity in an agrammatic patient: the relative impairment of verb retrieval and comprehension. Neuropsychologia, 23, pp. 709-727.
29. Caramazza, A. \& A. E. Hillis (1991) Lexical organization of nouns and verbs in the brain. Nature, 349, pp. 788790.

30. Bates, E. \& S. Chen (1991) The noun-verb problem in Chinese aphasia. Brain and Language, 41, pp. 203-233.

31. Damasio, A. \& D. Tranel (1993) Nouns and verbs are retrieved with differently distributed neural systems. Proceedings of the National Academy of Arts and Sciences of the USA, 90, pp. 4957-4960.

32. Damasio, H.; Grabowski, T. J., Tranel, D.; Gucgwa, R. D. \& A. Damasio (1996) A neural basis for lexical retrieval. Nature, 380, pp. 499-505. 